\title{
MARKETING OF LIBRARY AND INFORMATION PRODUCTS AND SERVICES: AN OVERVIEW
}

\author{
ARUNKUMAR H S \\ ASSISTANT LIBRARIAN \\ Karnataka Sanskrit University Bengaluru, Karnataka \\ RAMANI MOHAN \\ ASSISTANT LIBRARIAN \\ Bangalore University library BANGALORE
}

\begin{abstract}
Marketing of library and information services is a nascent development in our country. The paper discusses and emphasizes the need for the adoption of marketing approach by the university libraries to augment their financial resources and exploit new information technology to provide better information support to the users. Highlights the marketing concept and its various activities and how these activities can be successfully applied in the marketing of library and information products and services in university libraries. Also discusses on the problems in implementing marketing concept to library and information services. Provides various definitions of marketing.
\end{abstract}

Key words: Marketing, Information Products

Cite this Article: Arunkumar H S and Ramani Mohan, Marketing of Library and Information Products and Services: an Overview. International Journal of Library \& Information Science, 7(2), 2018, pp. 39-44.

http://iaeme.com/Home/issue/IJLIS?Volume=7\&Issue=2

\section{INTRODUCTION}

Marketing has been one of the oldest professions. Of course the formal study of marketing started only in the 1920's. Marketing has been maligned and misunderstood for most of its existence as wasteful. Intrusive and unprofessional. It is also equated sometimes with advertising or selling. These activities an many more are part of modern marketing operation. Perhaps one can be successful in marketing by giving the customer what he wants at the right price and by making it available at the right place and at the right quantity. 


\section{MARKETING SERVICES}

Services marketing are a sub field of marketing, which can be split into the two main areas of goods marketing (which includes the marketing of fast moving consumer goods (FMCG) and durables) and services marketing. Services marketing typically refer to both business to consumer (B2C) and business to business (B2B) services, and include marketing of services like telecommunications services, financial services, all types of hospitality services, car rental services, air travel, health care services and professional services. The range of approaches and expressions of a marketing idea developed with the hope that it be effective in conveying the ideas to the diverse population of people who receive it. Services are economic activities offered by one party to another. Often time-based, performances bring about desired results to recipients, objects, or other assets for which purchasers have responsibility. In exchange for money, time, and effort, service customers expect value from access to goods, labor, professional skills, facilities, networks, and systems; but they do not normally take ownership of any of the physical elements involved.

\section{MARKETING STRATEGY IN LIBRARIES}

Once marketing opportunities have been identified, a strategy must be formulated for taking advantages of them. Strategy in the broadest sense is a dynamic, action oriented blue print accomplishing the organizations mission, goals and objectives. Marketing strategy involves determining the level, mix and allocation of the marketing effort over a time.

A productive marketing strategy requires that all aspects of the marketing mix be considered. The components of an overall marketing strategy are products planning, distribution strategy, promotional strategy and pricing strategy. Marketing mix components are subsets of the overall marketing strategy.

\section{DEFINATION}

Stanton (1981): "marketing is a total system of interacting business activities to plan, price, promote and distribute want satisfying products \& services and present to potential customers".

Philp Kotler (1996) "Marketing is the analysis, planning implementation, and control of carefully formulated programmes designed to bring about voluntary exchanges of values with target markets for the purpose of achieving organizational objectives. It relies heavily on designing the organization's offering in terms of the target market's needs and desires and on using effective pricing, communication and distribution to inform, motivate and service the markets".

Zachert and Williamss considered that' 'marketing is planning that focuses on products place or mode of delivery, adjustment of cost/price to the market, and promotion to ! Specifically targeted segments of the special librarian's market."

The above definitions call for various activities in marketing. They are:

1. Development of products and services

2. Pricing

3. Distribution

4. Promotion

5. Evaluation of products and services.

All the above mentioned activities of marketing as applied to other industrial sectors are equally applicable in the area of information products and services. Whether it is for profit or non-profit sector, methods remain the same while the policy varies. 


\section{INFORMATION MARKETING IN UNIVERSITY LIBRARIES IN INDIA}

It can be said that the concept of information marketing is still in a state of infancy in university libraries in India. Factors which haracterise the difficulties of information marketing are:

$>$ Lack of proper assessment of requirements, wants and needs of the users,

$>$ Casual approach in supplying information to the potential users,

$>$ Lack of perception of how much information services and products can contribute to boost research and development activity,

$>$ Lack of perception of the economic aspect of buying information on the part of the user of information.

The recognition of information as a commodity or organizational resource is not very new in the developed countries. But the situation is different in a developing country like India. In the university environment, it still sounds strange to think of information as a marketable commodity. In the university, the main objective is the growth of knowledge and stimulation of research while in a market, the main objective is profit making.

To accelarate the pace of research and development, it looks imperative to find a confluence point of the academic and business approach to strike a balance between the two, so that the users can get the needy information for a payment and without wasting much of their precious time

\section{PRODUCT}

Kotler's Definition of product is "anything that can be offered to a market for attention, acquisition, use or consumption that might satisfy a want or need. It includes physical objects, services, persons, places, organizations and ideas". The library and information centres provide a range of products and services to its community, including the collection, reference/information services, access to the collection and professional expertise, bibliographic instruction and other programming, and so forth. Some of the products are traditional and have been in existence for many years. Other products have been developed more recently, such as online searching, microcomputer for in-library use and databases on CR-ROM, to name a few.

The library's products can be arranged with the following three dimensional structures:

COLLECTION- Books, Periodicals, Videos and Films, audio recording and CDROM etc.

$>$ SERVICES- Circulation, interlibrary loan, online searches, reference service, CAS, SDI etc.

PROGRAMS- Bibliographic instruction, displays, lecturers etc.

\section{PLACE}

In the marketing mix elements, place or distribution refers to the creation of special utility to the consumers. It comprises of management of distribution channel and physical distribution of products. Physical distribution is set of interdependent organization involved in the process of making a product or service available for use or consumption by the consumer. There are two dimensions of the physical distribution process the flow of information from the individual consumer or organizer to the producer and to the consumer or the user. So far the library is concerned, place become a major issue for library service. Traditionally, place has meant the physical location of branch, academic and central libraries. Computerized 
networks, remote access through computer modems and electronic mail and delivery systems have changed the sense of place to include more than physical access to the library. Communication media such as mail, telephone, TV and computer terminals form important distribution channels.

\section{PRICE}

The price is the amount a customer pays for the product. The price is very important as it determines the company's profit and hence, survival. Adjusting the price has a profound impact on the marketing strategy, and depending on the price elasticity of the product, often it will affect the demand and sales as well. The marketer should set a price that complements the other elements of the marketing mix. When setting a price, the marketer must be aware of the customer perceived value for the product. Three basic pricing strategies are: market skimming pricing, market penetration pricing and neutral pricing. The 'reference value' (where the consumer refers to the prices of competing products) and the 'differential value' (the consumer's view of this product's attributes versus the attributes of other products) must be taken into account.

Distribution is the marketing activity concerned with distributing the product from the manufacturer to the customer, making the product available and easy to buy.

Following are the major channels of dissemination:

$>$ Interpersonal delivery

$>$ Group personal delivery

$>$ Strategic placement

$>$ In-house dissemination

$>$ Local depositories

$>$ Mass media

$>$ Broadcasting

$>$ Mail

$>$ Telephone

$>$ Computer network

\section{PROMOTION}

Promotion is an important in marketing mix, but it has received more attention then other elements it is considered synonyms which marketing promotion is widely practiced by all library and information professionals.

Promotion uses all the tools of public relations persuasive communication, advertising, personal selling, publicity and incentive. The purpose of promotion is to communicate, to convince and to compete, promotion in library and information centre can be taken care in following way:
* Personal Contact
* Public relations
* Advertisement
* Personal selling
* Incentives
* Publicity 


\section{PRINCIPLES OF MARKETING MANAGEMENT}

Modern library services should be based on the following marketing principles.

- The Company must have an active attitude towards the market. It cannot expect customers to buy a product simply because it is produced. The management must actively study the market, persuade customers, promote the product, and organize distribution.

- Marketing should be given at least as much importance as other basic functions such as administration, production and finance.

- The marketing function must be "integrated". This means that the various marketing considerations must be taken into account in the decisions of all the managers, not only those directly concerned with sales.

\section{MARKETING TECHNIQUES:}

Management is required to control the application of a range of skills and techniques in marketing, generally derived from practical industrial experience and from modern social sciences such as economics, statistics and applied psychology. Marketing skills and techniques can be divided into four broad groups.

- Those used in order to obtain data about the market

- Those used to create and stimulate demand

- Those used to analyze costs and other marketing factors

- Other practical skills and techniques

\section{MARKETING TECHNIQUES IN LIBRARY MANAGEMENT: FUTURE VIEWPOINTS}

1. Body of specialized knowledge and technical skills; library profession required specialized knowledge and technical skill, therefore marketing techniques provides technical skills set for future library manager.

2. Formal training and experience; it required serious preparation for acquiring the necessary knowledge and method for applying knowledge for work and technical skills with high qualification thus, marketing is useful for library management and it can be useful in library future.

3. An ethical code or standard of conduct; marketing management is useful for library, in this regard there should ethical code and standard conduct according to marketing method to provide quality services to the user and manager of the library within the available budget of library.

4. A commitment to public service rather than to monetary gain; the marketing management values teach that the main aim being to reduce public services, therefore, it is required that its members should regard services than monetary gain. Librarianship as a service profession therefore the users are regarded as the king.

5. Financial return not the measure of success; financial return is not regarded as a measure of success, according to marketing management philosophy, changing value of library professionals have sometimes given more value to financial return when this is not desirable. 


\section{CONCLUSION}

The library can be called an information market and the library user is a consumer of information. Information is a vital resource for national development. Increasing realization of the role of information has resulted in the establishment of information systems to provide a variety of information services and products. It is an essential step in the planning, designing, and use of such services and products for optimal use of information. Library acquisition, organization and dissemination must be based on the modern concept of marketing to achieve reader satisfaction. It must endeavor to nurture culture of customer service to enhance its image in the eyes of the users.

\section{REFERENCES:}

[1] Dworkin, Kristine. (2003). Internal marketing: Breaking the barriers, In: An Integrated approach to services marketing: a book of readings for library and information services, Edited by Dinesh K. Gupta and Ashok Jambhekar, Mumbai: Allied, 272-278.

[2] Freeman, James E and Ruth M. Katz. (1978). Information marketing In: Annual Review of Information Science and Technology, 13, White Plains, New York: Knowledge Industry Publications Inc.

[3] Renborg, Greta. (1997). marketing library services: how it all began, Proceedings of the 63rd IFLA General Conference (CD-ROM).

[4] Tucci, Valerie K. (1988). Information marketing in libraries, In: Annual Review of Information Science and Technology, Vol. 23, BV Elsevier Science Publishers for ASIS.

[5] Kotler, Philip. (1995) Marketing for Nonprofit Organizations. 2nd ed. New Delhi Prentice-Hall of India.

[6] Weingand, D. E. (1995). Preparing for the new millennium: the case for using marketing strategies.Library Trends, 43(3).

[7] Shapiro, B. P. (1981). Marketing of non-profit organizations. In: The Marketing of Library andInformation Services, ed. by Blaise Cronin. London: Aslib, 26-27.

[8] Webber, S. (1999). Marketing library and information services. Inform (Newsletter of the instituteof Information Scientists). Latest Update, Nov. 13, 1999.

[9] Gumbs, B. (1999). How to develop a marketing plan. In: Marketing Information Products andServices: A Primer for Librarians and Information Professionals, ed. by Jain, A. K. et. al. New Delhi:Tata McGraw-Hill, 202-225. 